\title{
Adiponectin as a potential biomarker of vascular disease
}

\author{
This article was published in the following Dove Press journal: \\ Vascular Health and Risk Management \\ 16 January 2015 \\ Number of times this article has been viewed
}

\author{
Mehrangiz Ebrahimi- \\ Mamaeghani' \\ Somayeh Mohammadi ${ }^{2}$ \\ Seyed Rafie Arefhosseini ${ }^{3}$ \\ Parviz Fallah ${ }^{4}$ \\ Zahra Bazi ${ }^{5}$ \\ 'Nutrition Research Center, \\ ${ }^{2}$ Department of Nutrition, \\ ${ }^{3}$ Department of Food Technology, \\ Faculty of Nutrition Sciences, Tabriz \\ University of Medical Sciences, Tabriz, \\ ${ }^{4}$ Department of Molecular Biology \\ and Genetic Engineering, Stem Cell \\ Technology Research Center, Tehran, \\ ${ }^{5}$ Department of Biotechnology, \\ Faculty of Medicine, Shahid Beheshti \\ University of Medical Sciences, Tehran, \\ Iran
}

Correspondence: Somayeh Mohammadi Department of Nutrition, Faculty of Nutrition Sciences, Tabriz University of Medical Sciences, Attar Neishaboori Ave, PO Box 51666147II, Tabriz, Iran

Tel +984 II 3357580

Fax +98 4II 3340634

Email mohammadis.phd@gmail.com
Abstract: The increasing prevalence of diabetes and its complications heralds an alarming situation worldwide. Obesity-associated changes in circulating adiponectin concentrations have the capacity to predict insulin sensitivity and are a link between obesity and a number of vascular diseases. One obvious consequence of obesity is a decrease in circulating levels of adiponectin, which are associated with cardiovascular disorders and associated vascular comorbidities. Human and animal studies have demonstrated decreased adiponectin to be an independent risk factor for cardiovascular disease. However, in animal studies, increased circulating adiponectin alleviates obesity-induced endothelial dysfunction and hypertension, and also prevents atherosclerosis, myocardial infarction, and diabetic cardiac tissue disorders. Further, metabolism of a number of foods and medications are affected by induction of adiponectin. Adiponectin has beneficial effects on cardiovascular cells via its antidiabetic, anti-inflammatory, antioxidant, antiapoptotic, antiatherogenic, vasodilatory, and antithrombotic activity, and consequently has a favorable effect on cardiac and vascular health. Understanding the molecular mechanisms underlying the regulation of adiponectin secretion and signaling is critical for designing new therapeutic strategies. This review summarizes the recent evidence for the physiological role and clinical significance of adiponectin in vascular health, identification of the receptor and post-receptor signaling events related to the protective effects of the adiponectin system on vascular compartments, and its potential use as a target for therapeutic intervention in vascular disease.

Keywords: obesity, adiponectin, vascular disease

\section{Introduction}

The association between obesity and increased mortality rates is due to the increasing prevalence of a number of cardiovascular disorders, such as ischemic heart disease and stroke. Adipose tissue is a dynamic endocrine organ that secretes a variety of hormones known as adipokines. Adipokines secrete into the circulation and participate in regulation of a number of chronic diseases affecting insulin sensitivity, glucose, and lipid metabolism, as well as cardiovascular homeostasis. ${ }^{1-4}$ In obesity, complicated metabolic status is created as a result of some inflammatory cells infiltration to adipose tissue especially activated macrophages. Under these conditions, adipose tissues produce proinflammatory adipokines such as tumor necrosis factor-alpha (TNF- $\alpha$ ), leptin, interleukin (IL)-6, monocyte chemoattractant protein-1, lipocalin-2, resistin, adipocyte fatty acid binding protein, and plasminogen activator inhibitor-1, that encourage vascular disease. ${ }^{5}$ In these circumstances, production of adiponectin is markedly reduced. All of these changes have been shown to be key contributors to obesity-related vascular disease. Adiponectin is a protein hormone produced by adipose tissues, including white adipose tissue, and has 
vasoprotective properties. ${ }^{6,7}$ It is released into the blood stream at a concentration of around $0.01 \%$ of all plasma protein, ie, approximately $0.5-30 \mu \mathrm{g} / \mathrm{mL}$, and the plasma concentration of adiponectin is 1,000-fold higher than that of most other hormones, including insulin. ${ }^{8}$ In vivo and in vitro studies in 1995-1996 identified adiponectin as a novel signaling protein in adipose tissue that was probably involved in the regulation of insulin. ${ }^{9-12}$ In recent studies, hypoadiponectinemia has also been shown to be associated with hypertension, dyslipidemia, and inflammation in both the general population and in diabetic patients. ${ }^{2,13,14}$ Adiponectin plays a role in the protection and inhibition of various metabolic disorders, including type 2 diabetes, ${ }^{15}$ obesity, and atherosclerosis, and in particular has a vasoprotective effect. ${ }^{16}$ Here, we summarize and review the studies reported from 1991 to 2014 on the role of adiponectin in vascular disease. We focus on recent evidence for the physiological role and clinical significance of adiponectin in vascular health, identification of the receptor and post-receptor signaling events related to the protective effects of the adiponectin system on vascular compartments, and its potential use as a target for therapeutic intervention in vascular disease.

\section{Biology and structure}

Adiponectin is a hormone with a protein structure and is synthesized exclusively by adipocytes. ${ }^{11}$ It is also known as Acrp30, GBP28, adipoQ, or apM1, and has been mapped to chromosome 3 q27, which has also been linked to type 2 diabetes. Secreted by glands in white fat, adiponectin contains 244 amino acids and four distinct domains, a short signal sequence that targets hormone secretion from outside the cell, a short region that differs between species, and a globular domain with 65 amino acids that is similar to collagenous protein. A collagen domain is located at the N-terminus and a globular domain at the C-terminus. ${ }^{17}$ Adiponectin circulates in plasma in three forms: as a low molecular weight trimer, as a trimer-dimer or middle molecular weight hexamer, and as a high molecular weight (HMW) 12-18 mer form. ${ }^{18,19}$ Its domain structure is similar to that of complement protein C1q. ${ }^{11}$

In humans, adiponectin circulates mainly as a low molecular weight (180 kDa) hexamer and an HMW multimer (about $360 \mathrm{kDa}$ ). In human plasma, the globular form of adiponectin, a full-length protein or a proteolytic cleavage product of adiponectin, which leaves only the globular head domain intact, circulates at very low levels (Figure 1). ${ }^{20}$ The crystal structure of the globular domain of adiponectin bears a marked similarity to the structure of TNF- $\alpha .{ }^{17}$ The octameric structure of HMW adiponectin has been detected by sedimentation, equilibrium centrifugation, and gel electrophoresis. ${ }^{21}$

Studies in mice report that the half-life of circulating adiponectin is 75 minutes and that its clearance is mediated by the liver. Despite its rapid turnover, plasma clearance is slower for HMW adiponectin and its levels remain fairly constant in the circulation. ${ }^{22}$

The treatment with thiazolidinedione, sensitized vital hepatic function of insulin with enhancing serum levels of HMW adiponectin. ${ }^{23,24} \mathrm{HMW}$ adiponectin is the most active oligomeric form of adiponectin and is clearly associated with a number of metabolic disorders. It is thought that adiponectin has enhanced biological activity, including insulin action

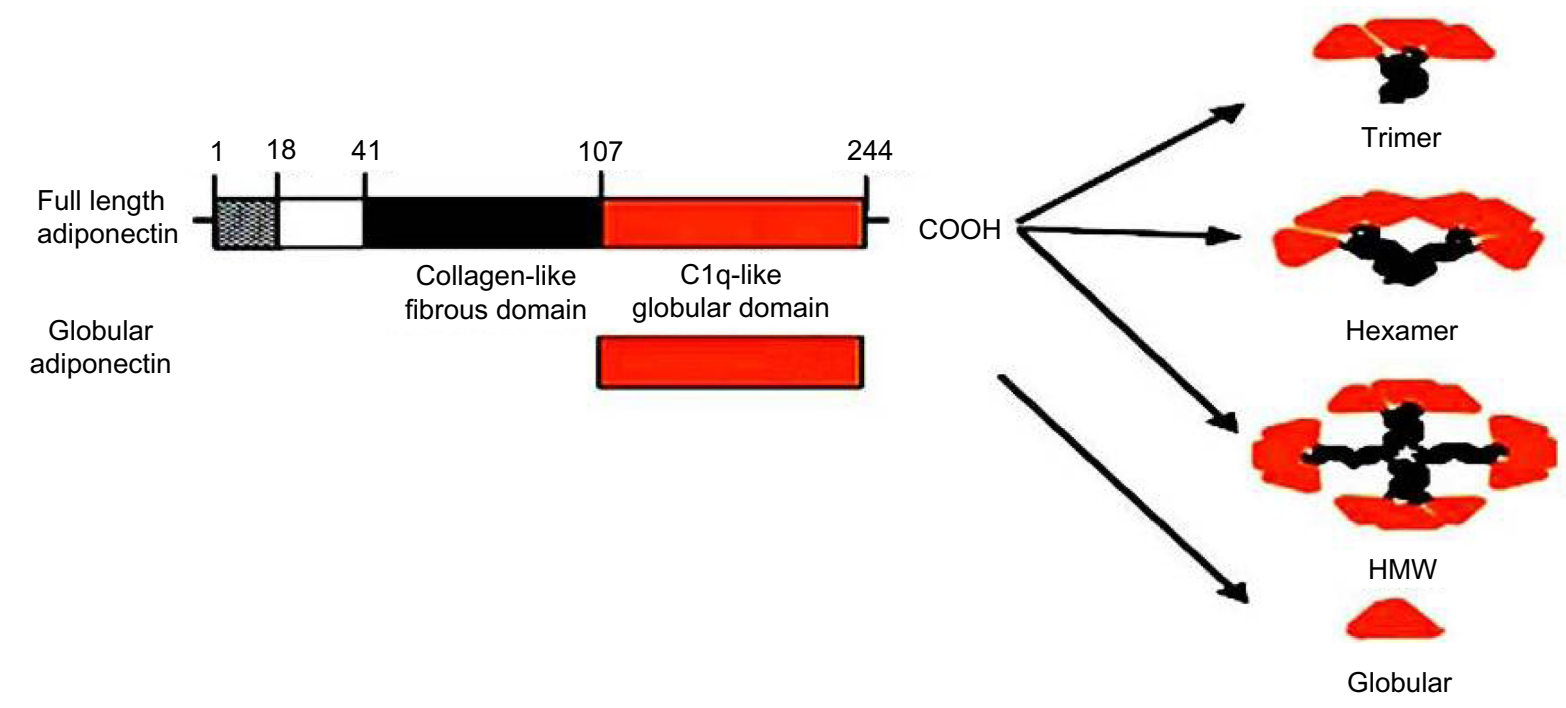

Figure I Domains and structure of adiponectin. Abbreviation: HMW, high molecular weight. 
and apoptosis suppression in cultured endothelial cells and activation of muscle AMP-activated protein kinase (AMP kinase). ${ }^{24,25} \mathrm{HMW}$ adiponectin can serve as a precursor pool of the hormone that is activated with low molecular weight adiponectin and is responsible for the impact of adiponectin on the activity of AMP kinase. In contrast with this, reduced serum concentrations of total adiponectin (not only HMW) have been reported in obesity, ${ }^{26}$ type 2 diabetes, ${ }^{27}$ and cardiovascular disease (CVD), ${ }^{28}$ and there is some evidence indicating a correlation between circulating levels of total/ HMW adiponectin and coronary heart disease, ischemic stroke, and peripheral arterial disease. ${ }^{29-31}$ There is also evidence of a proinflammatory effect of reduced concentrations of total adiponectin in human rheumatoid arthritis synovial fibroblasts, lymphocytes, and endothelial cells, which may predispose to CVD. ${ }^{32}$ Dessein et al demonstrated that total circulating adiponectin had a paradoxical effect on the risk of CVD in patients with rheumatoid arthritis. ${ }^{33}$ Thus, there are some controversies on different biological activities among various adiponectin isoforms that are partly due to difficulty in circulating isoforms determinations. ${ }^{34-36}$

\section{Adiponectin receptors}

The vascular actions of adiponectin are mediated by three receptors, ie, AdipoR1, AdipoR2, and T-cadherin. AdipoR1 and AdipoR2 are located integrally in the cell membrane with seven transmembrane domains, and the $\mathrm{N}$ terminus is located within the cell with inverted membrane topology. In AdipoR1, the short $\mathrm{C}$ terminus (with about 25 amino acids) is located externally in the cell membrane like G-protein coupled receptors, but is structurally and functionally distinct from classical G-protein coupled receptors. AdipoR1 is expressed in most cells, but its major expression is in skeletal muscle where it is associated with activation of AMP kinase pathways. AdipoR2 is abundantly expressed in the liver, where it is linked to activation of peroxisome proliferator-activated receptor (PPAR)- $\alpha$ pathways. ${ }^{37,38}$ Activated AdipoR1 and AdipoR2 increase mitochondrial biogenesis, improve oxidation of fatty acids in the liver and skeletal muscle, enhance glucose uptake in cells, reduce hepatic gluconeogenesis, increase lactate production in skeletal muscle, and inhibit inflammation and oxidative stress, which are important metabolic risk factors for cardiovascular disease. ${ }^{39,40}$

APPL1, an adaptor protein consisting of a PH pleckstrin homology domain, a phosphotyrosine binding domain, and a leucine zipper motif, interacts directly with AdipoR1 and AdipoR2. ${ }^{41,42}$ One of the important functions of APPL1 appears to be coupling of adiponectin receptors with their downstream signaling cascades, although the precise molecular mechanisms involved are not yet known. The intracellular portion of the adiponectin receptor interacts with the phosphotyrosine binding domain of APPL1, which results in mediation of downstream adiponectin signaling cascades and metabolic effects by APPL1. APPL1 has a key role in mediation of the adiponectin-dependent, insulin-signaling pathway in skeletal muscle and contributes to the anti-inflammatory and protective effect of adiponectin in endothelial cells. APPL1 acts as a signaling pathway mediator in cross-talk with adiponectin and insulin, interacts directly with membrane receptors and signaling proteins, and plays critical roles in cell proliferation, apoptosis, and survival, endosomal trafficking, and chromatin remodeling. Impaired adiponectin-stimulated AMP kinase and PPAR- $\alpha$ signaling are, respectively, the result of targeted disordered AdipoR1 and AdipoR2. In contrast, destruction of AdipoR1 and AdipoR2 causes insulin resistance and glucose intolerance because of impaired adiponectin connection to these receptors and its performance. ${ }^{38}$

AdipoR1 and AdipoR2 have been suggested to have opposing effects on the pathways for glucose and lipid metabolism. In a study by Bjursell et al, AdiopR1-null mice showed a diet-induced increase of fat and glucose intolerance. ${ }^{43}$ This result is the opposite with lean AdipoR2-null mice. ${ }^{43}$ In this study, deletion of AdipoR2 reduced the dyslipidemia and insulin resistance induced by a high-fat diet but promoted type 2 diabetes. ${ }^{44}$ The precise physiological roles of these two receptors need further clarification in future studies.

The T-cadherin-glycosyl phosphatidylinol-linked cell surface molecule was initially identified 2 decades ago as an axon guidance molecule and a modulator of neural crest cell migration. ${ }^{45}$ It is now appreciated that T-cadherin has functions that extend beyond the typical behavior of cadherin during cell-to-cell adhesion. T-cadherin is a hexameric HMW adiponectin receptor and is expressed on a number of cell types, including vascular endothelial cells, smooth muscle cells (SMCs), and pericytes. ${ }^{46}$ Its expression mainly increases in atherosclerotic regain. The activated form of T-cadherin protects vascular endothelial cells against apoptosis resulting from oxidative stress. ${ }^{47,48}$ Expression of T-cadherin is critical for the revascularization activity of adiponectin in vitro and in vivo ${ }^{49}$ however, the functional relevance of binding between adiponectin and T-cadherin is not understood (Figure 2).

\section{Anatomic location of adipose tissue}

Sectional adipose tissues due to its several metabolic factors have some considerable cardiometabolic effects, so, fat depots are separated based on their location and 


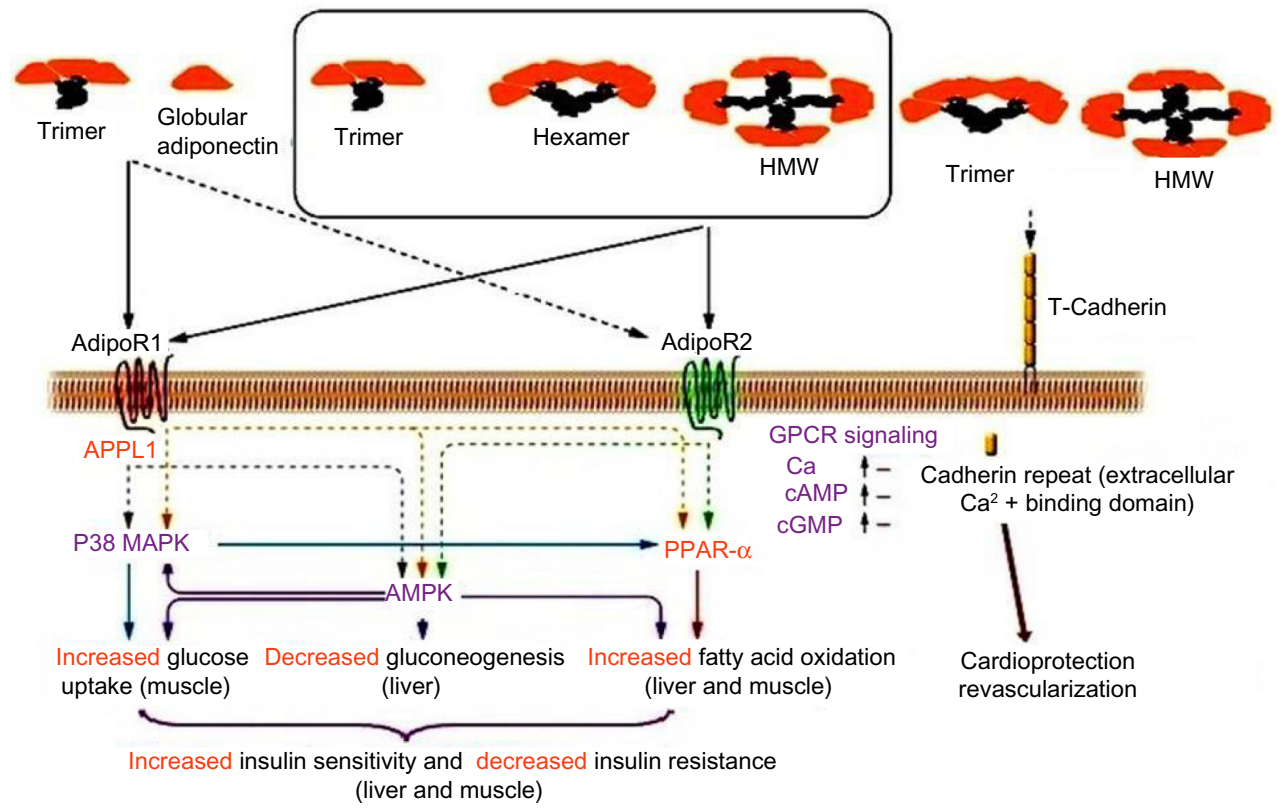

Figure 2 Adiponectin-mediated intracellular cardioprotective signaling pathways via adiponectin receptors. Abbreviation: $\mathrm{HMW}$, high molecular weight.

their association with local or systemic effects. The two major types of white adipose tissue are visceral fat (located in the mediastinum and abdominal cavity) and subcutaneous fat (located in the hypodermis). In visceral obesity, infiltration of macrophages and other types of inflammatory cells causes inflammation and production of more inflammatory cytokines that increase the risk of obesity-related metabolic disorders, such as insulin resistance, plasma lipid disorders, and CVD (Figure 3). In contrast, subcutaneous fat is a major source of adiponectin

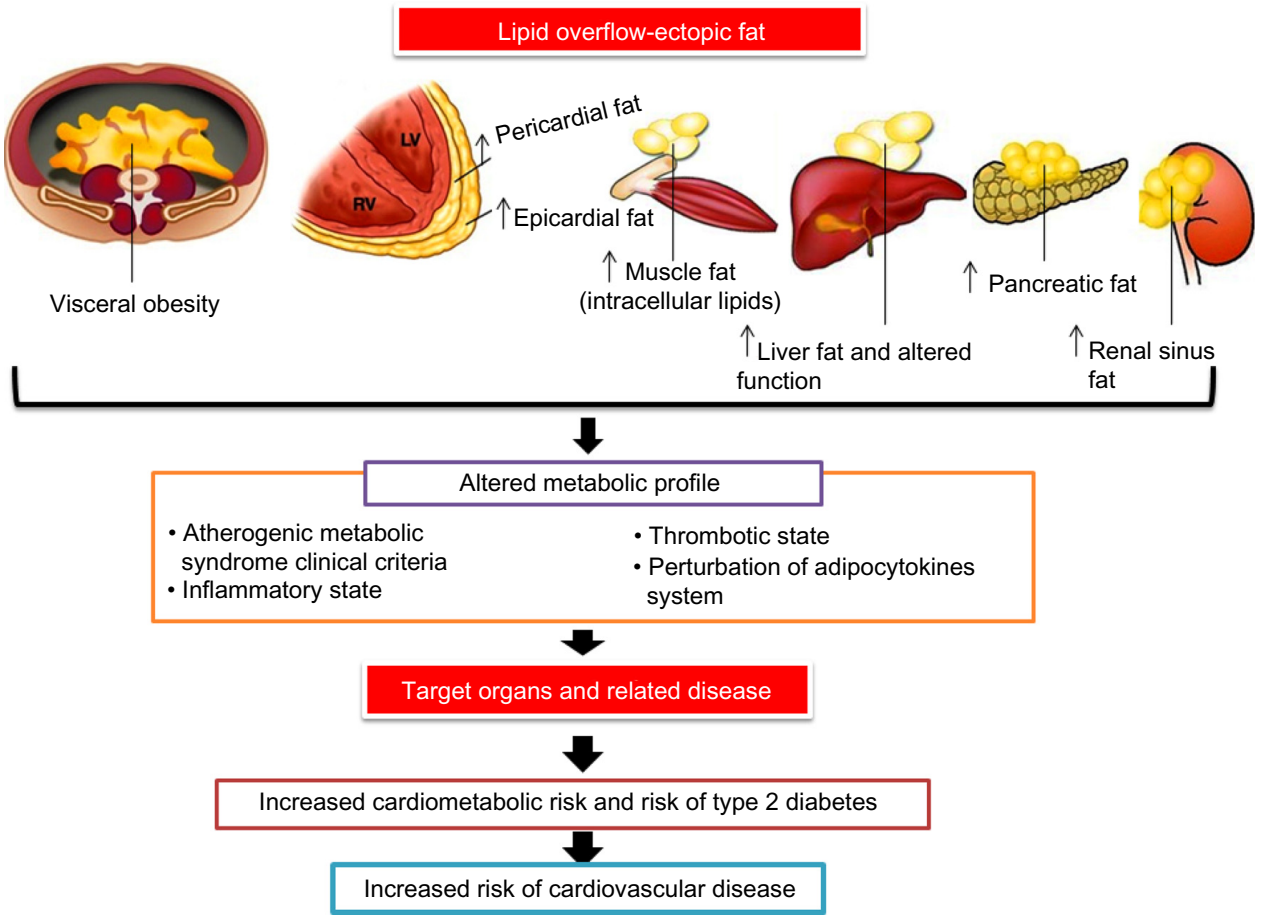

Figure 3 Working model showing how excess ectopic adiposity is associated with increased cardiovascular risk. Abbreviations: LV, left ventricle; RV, right ventricle. 
and leptin. The increase in subcutaneous fat is related to plasma lipid profiles. ${ }^{50}$

Because of the existence of adipose tissue between skeletal muscle cells, including intramyocellular and intermuscular fat, the percentage of skeletal muscle fat can be a risk factor for the development of insulin resistance and increased risk of CVD. ${ }^{51}$ Also, two anatomically distinct fat depots (epicardial and pericardial) cover the heart. Epicardial fat is located between the myocardium as intermuscular fat, and the visceral pericardium and pericardial adipose tissue located in the external layer of the pericardium (Figure 3). Epicardial adipose tissue provides the fuel used for skeletal and cardiac muscle work and contraction. ${ }^{51}$ In humans, epicardial adipose tissue makes up about $20 \%$ of total ventricular weight. It is located in the atrioventricular and interventricular grooves of both ventricles, and extends to the ventricular apex and the coronary arteries. ${ }^{52}$ Approximately $80 \%$ of the heart is covered by pericardial adipose tissue. This type of fat constitutes about $20 \%-50 \%$ of the weight of the human heart. ${ }^{50}$

In general, deposition of triglyceride droplets in nonadipose tissue is known as ectopic fat storage. Ectopic fat consists of peripheral tissues fat storage, ie, epicardial and pericardial fats, and is linked to tissue-specific insulin resistance, both in overweight individuals and those with normal weight. ${ }^{53,54}$ Adipocytes in epicardial fat are smaller than those in peritoneal and subcutaneous fat. In normal situations, epicardial and pericardial adipose fats are a vital local energy source for maintaining cardiac contractility by lipolysis of fats and release of fatty acids (Figure 3). Adipocyte size, in both epicardial and subcutaneous fat, is positively associated with insulin resistance and obesity-related cardiac dysfunction, and has a negative association with local adiponectin gene expression. Gene expression for adiponectin is decreased in subjects with coronary artery disease..$^{55,56}$ The morphology and function of adipose tissue is influenced by sex and anatomic location. Adipocytes in both subcutaneous and visceral depots are larger in size in obese males than in females. These fat storages are significantly correlated with proinflammatory cytokine expression. ${ }^{57}$

\section{Ability of adiponectin to protect against vascular disease}

Over the past several years, clinical findings generally support an etiological role of adiponectin deficiency in the development of various vascular complications in humans. ${ }^{58,59}$ Hypoadiponectinemia was found to be a significant predictor of endothelial dysfunction in both the peripheral and coronary arteries independent of insulin resistance index, body mass index, and dyslipidemia. ${ }^{60-62}$ Consistent with the clinical observations described above, it has been shown that adiponectin-deficient animal models are more susceptible to developing vascular disorders, neointimal hyperplasia after acute vascular injury, ${ }^{63,64}$ impaired endothelium-dependent vasodilation, ${ }^{65}$ and high blood pressure. ${ }^{66}$ Both adenovirusmediated overexpression of full-length adiponectin ${ }^{67}$ and transgenic overexpression of globular adiponectin ${ }^{64}$ resulted in marked alleviation of atherosclerotic lesions in apolipoprotein (apo)E-deficient mice, which showed a major improvement in endothelial dysfunction and hypertension. ${ }^{65,66}$ Treatment with adiponectin resulted in a significant reduction of atherosclerotic plaque area on the abdominal aorta in a rabbit model. Adiponectin-mediated attenuation of atherosclerosis in this model was associated with decreased expression of adhesion molecules, including vascular cell adhesion molecule- 1 and intercellular adhesion molecule-1. ${ }^{66}$ Therefore, adiponectin, in addition to having beneficial effects on insulin sensitivity and lipid metabolism, exerts multiple vasoprotective effects via its action on the vascular system, including endothelial cells, monocytes, macrophages, leukocytes, platelets, and SMCs, plaque formation, and development of thrombosis.

\section{Anti-inflammatory properties of adiponectin}

The anti-inflammatory properties of adiponectin are likely to be the major component of its beneficial effects in vascular disease. Many benefits of adipokine products in the cardiovascular system are attributable to adiponectin. Inflammatory conditions like obesity, insulin resistance, and ultimately diabetes mellitus are intertwined and closely associated with the development of vascular disease. ${ }^{68-70}$ This observation may explain the close link between obesity and atherosclerosis; however, the exact mechanism involved in the relationship between low-grade inflammation and fat remains unclear. C-reactive protein (CRP) is an inflammatory cytokine product and an independent risk predictor of vascular disorders like coronary heart disease. ${ }^{71,72}$ High CRP levels have been suggested to be a useful biomarker for chronic obesity-related inflammation. ${ }^{73}$ The biosynthesis of CRP takes place in the liver, but also occurs under inflammatory stress in other types of cells, including macrophages, SMCs, and endothelial cells in atherosclerotic lesions. ${ }^{74,75}$ Some inflammatory cytokines, eg, TNF- $\alpha$ and NFKB, are induced by the direct proinflammatory action of CRP. ${ }^{74}$ Adiponectin activates AMP kinase and NFKB activity in human aortic endothelial cells under hyperglycemic conditions. This adipokine decreases CRP 
messenger RNA and CRP protein, ${ }^{76}$ and inhibits stimulation of NF $\kappa$ B signaling and TNF- $\alpha$ secretion from macrophages. ${ }^{68}$ Adiponectin suppresses TNF- $\alpha$-induced monocyte adhesion to human aortic endothelial cells and the expression of certain other adhesion molecules. ${ }^{77}$ Consistent with these studies, adiponectin reduces expression of cell adhesion molecules and activation of IL- 8 and NFאB by decreasing TNF- $\alpha$ in endothelial cells. ${ }^{76,78}$

Some of the insulin-sensitizing and cardioprotective actions of adiponectin have been shown to be mediated by AMP kinase signaling in various cells, including hepatocytes, myocytes, and endothelial cells. ${ }^{40,79,80}$ Consistent with these findings, activation of AMP kinase by 5 -aminoimidazole4-carboxamide-1-beta-D-ribofuranoside inhibits fatty acidinduced NFKB activation in endothelial cells. ${ }^{81}$ Adiponectin modulates macrophage function and phenotype. ${ }^{82}$ Adiponectin inhibits the expression and activity of the class A macrophage scavenger receptor and suppresses transformation of macrophages to foam cells. ${ }^{83}$

It is revealed the decrease in expression of anti-inflammatory M2-type markers and reactive oxygen species (ROS) generation and increase in the expression of proinflammatory M1-type markers of peritoneal macrophages and stromal vascular fraction cells in adiponectin-deficient mice. It may be because of the stimulation of the arginase- 1 expression in these special cells and stimulation of them with recombinant adiponectin. ${ }^{84}$

The promotion of phagocytosis by macrophages has been performed by including options to form a bridge between dead cells and macrophages by adiponectin like other members of the collectin family of proteins. ${ }^{85}$ This activity is mediated by binding of adiponectin to calreticulin and CD91 on the surface of the macrophage and recognition motifs referred to as apoptotic cell-associated molecular patterns on the dead cell surface. Therefore, abnormally low levels of adiponectin could considerably impair the clearance of cell apoptosis. Especially, none of the adiponectin receptors (AdipoR1, AdipoR2, and T-cadherin), are demanded for the phagocytotic activities of adiponectin. ${ }^{85}$ The lower adiponectin receptors have been manifested in monocytes of overweight/obese subjects with type 2 diabetes $^{86}$ and CVD patients. ${ }^{87}$

Stimulation of IL-10 and IL-1 receptor antagonists is one of the anti-inflammatory actions of adiponectin in human monocytes, monocyte-derived macrophages, and dendritic cells. ${ }^{88}$ Decreased surface expression of adiponectin receptors in peripheral monocytes, together with reduced adiponectin-induced IL-10 secretion from macrophages, has been reported in patients with coronary artery disease. ${ }^{87} \mathrm{Via}$ induction of IL-10, adiponectin selectively increases tissue inhibitor of metalloproteinases-1 (TIMP-1) expression in human monocyte-derived macrophages, ${ }^{89}$ and adiponectin has a negative relationship with the matrix metallopeptidase (MMP)-9/TIMP-1 ratio in patients with acute coronary syndrome. ${ }^{90}$ It has been confirmed that, with induction of IL-10, adiponectin selectively increases expression of TIMP-1 in human monocyte-derived macrophages. ${ }^{89}$ TIMP-1 levels and the MMP-9/TIMP-1 ratio are independent predictors of the stability of atherosclerotic plaque and the severity of coronary atherosclerosis. Plasma adiponectin also has a negative relationship with other markers of inflammation and atherosclerosis, including adipocyte fatty-acid-binding protein $^{91}$ and lipocalin-2. ${ }^{92}$ Adiponectin in macrophages can alter multiple pathways of lipid metabolism in macrophages, including downregulation of sterol O-acyltransferase 1, which catalyzes the formation of cholesterol esters in cultured human monocyte-derived macrophages ${ }^{93}$ and reduces lipid accumulation in human THP-1 macrophage foam cells.

Finally, macrophages converted with the adiponectin gene demonstrate reduced oxidized low-density lipoprotein (LDL) uptake and elevated high-density lipoprotein-mediated cholesterol efflux. ${ }^{94}$ A gradual decrease in Toll-like receptor (TLR)4 signaling, attenuation of inflammatory activation, and an interaction between cardiac and immune cells account for the protective function of adiponectin against inflammation and injury in autoimmune myocarditis. These findings suggest that adiponectin has a protective effect against systemic inflammation. ${ }^{95}$

\section{Adiponectin in regulation of endothelial function}

Clinical observations indicate that there is a close relationship between hypoadiponectinemia and peripheral arterial dysfunction. ${ }^{65,66,96}$ The first and essential event in the development, progression, and appearance of hidden macroangiopathy involves endothelial dysfunction. ${ }^{97}$ Circulating levels of total adiponectin are inversely related to the risk of myocardial infarction. ${ }^{96,98}$ A comparison of adiponectin knockout mice and their wild-type littermates showed significantly increased neointimal hyperplasia, ${ }^{63,64}$ disordered endothelium-dependent vasodilation, and increased blood pressure. ${ }^{65}$ Flow-mediated dilation of the brachial artery has a significant relationship with plasma HMW adiponectin levels in young healthy men and could be used for assessment of endothelial function. In this way, assessment of HMW adiponectin could be a more useful indicator than assessment of total adiponectin for evaluation 
of endothelial dysfunction before any overt vascular disease is apparent. ${ }^{61}$

The vasodilation activity of adiponectin affects endothelial function by inhibition of ROS production as well as monocyte adhesion. Activation of AMP kinase that leads to an increase in endothelial nitric oxide (NO) synthase (eNOS) activity and NO production is mediated by the action of adiponectin. Biosynthesis of NO is performed by AMP kinase and is mediated via phosphorylation of eNOS at Ser $1177^{76}$ and Ser633 $3{ }^{99}$ by both the full-length and globular domains of adiponectin. The vascular system is protected by endothelialderived NO, which enhances vasodilation and inhibits platelet aggregation, monocyte adhesion, and SMC proliferation. ${ }^{100}$ Regulation of adiponectin-induced phosphorylation of AMP kinase at Thr172 and eNOS at Ser1177 has recently been demonstrated. ${ }^{101}$ Adiponectin also determines formation of the complex between heat shock protein 90 and eNOS that is required for enzyme activation. ${ }^{101-103}$ The signaling events linking AdipoRs and activation of AMP kinase/eNOS are not clear, but it is believed that the key mediator molecule may be APPL1. ${ }^{41}$

An impaired vasodilator response of the small mesenteric vessels to adiponectin has been shown in relation to APPL1 expression in both Zucker diabetic fatty rats and $d b / d b$ obese mice. ${ }^{41,104}$ This finding suggests a key role of APPL1 as a signaling relay point that mediates the adiponectin-induced cellular signaling cascade leading to production of NO. However, overexpression of an active AMP kinase can increase activation of eNOS and production of NO, even in conditions of suppressed APPL1 expression, ${ }^{41}$ suggesting that AMP kinase acts downstream of APPL1 and is directly responsible for both phosphorylation of eNOS at Ser and its interaction with heat shock protein 90. There is some evidence suggesting involvement of phosphoinositide 3-kinase in adiponectin-induced production of endothelial NO, possibly via activation of AMP kinase..$^{99,103,105}$ The key feature of oxidative stress is the increased production of vascular ROS, resulting in the quenching of $\mathrm{NO}$ and activation of proinflammatory signaling pathways such as protein kinase $\mathrm{C}$ and NF $\kappa \mathrm{B} .{ }^{106}$ Adiponectin improves the redox state in human vessels by restoring eNOS coupling, indicating a novel role of vascular oxidative stress in the regulation of adiponectin expression in human perivascular fat. ${ }^{107}$

Production of ROS is inhibited by adiponectin, and this metabolic function is possibly induced by high glucose concentration, ${ }^{108}$ basal and oxidized LDL, ${ }^{109,110}$ and palmitate $^{111}$ in endothelial cells. This activity is produced by suppression of nicotinamide adenine dinucleotide phosphate oxidase.

The antioxidant activity of adiponectin is mediated by the cyclic AMP/protein kinase A pathway ${ }^{108}$ and AMP kinase. ${ }^{111}$ Aortic rings in adiponectin knockout mice show higher superoxide anion and peroxynitrite concentrations, which can be reversed when these mice are treated with recombinant adiponectin. $^{112}$

In Wistar rats, augmentation of adiponectin was able to improve left ventricular dysfunction induced by chronic intermittent hypoxia and associated myocardial apoptosis by inhibition of ROS-dependent endoplasmic reticulum stress. ${ }^{113}$ The first step in this inflammatory reaction during development of atherosclerosis involves activation of endothelial cells and is characterized by increased expression of adhesion molecules (including intercellular adhesion molecule-1, vascular cell adhesion molecule-1, and E-selectin) and monocyte attachment. ${ }^{78}$

Adiponectin inhibits the interaction between leukocytes and endothelial cells by reducing the expression of E-selectin and vascular cell adhesion molecule- 1 and by increasing endothelial NO. ${ }^{108}$ This adiponectin-related decrease in expression of adhesion molecules has been demonstrated in an animal model of atherosclerosis. ${ }^{114}$ Adiponectin inhibits this step by suppressing the expression of adhesion molecules after induction by TNF- $\alpha$, resistin and IL-8, which, in turn, results in attenuation of monocyte attachment to endothelial cells. $^{78}$

The inhibitory effect of adiponectin on leukocyte adhesion and expression of adhesion molecules can be reversed by inhibition of eNOS, suggesting a need for eNOS/NO signaling for the anti-inflammatory actions of adiponectin in endothelial cells. Further, adenovirus-mediated expression of adiponectin in the aortic tissue of apoE-deficient mice and atherosclerotic rabbits inhibits expression of adhesion molecules. ${ }^{67,105}$ This anti-inflammatory activity of adiponectin is regulated in endothelial cells by protein kinase A-dependent inhibition of NFKB via AMP kinase-dependent and AMP kinase-independent mechanisms. ${ }^{76,115}$ However, acute treatment of endothelial cells with globular adiponectin activates $\mathrm{NF} \kappa \mathrm{B}$ and enhances the expression of adhesion molecules and monocyte chemoattractant protein-1 via activation of the sphingosine kinase signaling pathway. ${ }^{116}$ These inconsistencies may be attributed to the different forms of adiponectin or different incubation times used in different studies. Indeed, there is evidence that different oligomeric forms of adiponectin may have opposite functions with regard to modulating NFאB activity in $\mathrm{C} 2 \mathrm{C} 12$ myotubes. ${ }^{117}$ Adiponectin inhibits 
high glucose-induced IkB phosphorylation, NFкB binding activity, and production of CRP in human aortic endothelial cells. ${ }^{118}$

Since overexpression of AdipoRs increases the inhibitory effect of adiponectin on endothelial expression of adhesion molecules, AdipoRs can be assumed to have an important role in regulating the anti-inflammatory effect of adiponectin in the endothelium..$^{5}$ In atherosclerotic lesions, local apoptosis of endothelial cells increases their turnover rate and is involved in atherosclerosis. These lesions can be induced by high glucose, angiotensin II, palmitate, and oxidized LDL. ${ }^{111}$ HMW adiponectin inhibits caspase 3 activity in human umbilical vein endothelial cells via activation of the AMP kinase signaling pathway. ${ }^{119}$ In human umbilical vein endothelial cells, the globular domain of adiponectin inhibited angiotensin II-induced apoptosis in a dose-dependent manner, possibly through activation of eNOS and the interaction between eNOS and heat shock protein $90 .{ }^{5}$ By synthesis of NO through the phosphoinositide 3-kinase/AKT and AMP kinase signaling pathways, globular adiponectin reduces irregular high glucose-induced apoptosis and oxidative stress in human umbilical vein endothelial cells. ${ }^{120}$ The effects of adiponectin in terms of vascular endothelial damage and apoptosis via AMP kinase activation are dependent on binding of adiponectin to AdipoR1 on the cell surface. ${ }^{121,122}$ Activation of AMP kinase via the endosomal adaptor protein (consisting of phosphotyrosine binding, pleckstrin homology domains, and leucine zipper motif) regulates the protective effects of adiponectin against angiotensin II cytotoxicity on vascular cells. ${ }^{122}$

\section{Adiponectin and adaptive immunity}

In obesity, low-grade inflammation normally occurs in adipose tissue as a result of chronic activation of the innate immune system. This can explain the relationship between this anthropometric status of a person and the production of atherosclerosis. ${ }^{69}$ Adiponectin, with its anti-inflammatory property that was mentioned in "Anti-inflammatory properties of adiponectin", inhibits T-lymphocyte recruitment and accumulation in macrophages. In human monocyte-derived macrophages stimulated with lipopolysaccharide, adiponectin suppresses the expression of a range of chemokines, including the T-lymphocyte chemoattractants interferon gamma-inducible protein (IP)-10 (CXCL10), IFN-inducible T-cell $\alpha$ chemoattractant (CXCL11), and Mig (CXCL9). These chemokines together with their receptor CXCR3, are expressed by various types of cells in human atheroma, including macrophages, endothelial cells, and smooth muscle cells. ${ }^{123}$ These chemokines potently induce T-lymphocyte chemotaxis and recruit activated $\mathrm{T}$ lymphocytes during atherogenesis. ${ }^{124}$

The TLR4 signaling pathway is involved in the development of atherosclerosis and insulin resistance. TLRs recognize specific microbial components and activate innate immunity pathways, so interact with proinflammatory pathways by activation of endogenous inflammatory ligands. ${ }^{125}$ Adiponectin is selectively involved in prevention of atherosclerosis and insulin resistance by its interaction with the TLR4 pathway. ${ }^{125-127}$ Activation of transcription factor 2 and NFKB, which are involved in the MyD88dependent pathway, is reduced by adiponectin. This effect of adiponectin on $\mathrm{NF \kappa B}$ is in agreement with previously published results using lipopolysaccharide-stimulated macrophages and TNF- $\alpha$-stimulated human aortic endothelial cells. ${ }^{76,78,128}$ Therefore, in nonobese subjects, higher levels of adiponectin may efficiently reduce the proinflammatory functions of these chemokines. Accompanying in vitro findings, in vivo evidence showed raised plasma levels of interferon gamma-inducible protein-10, increased accumulation of T lymphocytes within lesions, and accelerated the development of atherosclerosis in E-null mice with lack of adiponectin. $^{26}$

Adding adiponectin to polyclonal activated CD4+ T lymphocytes induced messenger RNA expression and secretion of protein for interferon-gamma and IL-6, enhanced phosphorylation of p38 mitogen-activated protein kinase, and STAT 4, a transcription factor belonging to the signal transducer and activator of transcription protein family, and increased T-bet expression without any effect on cell proliferation. Therefore, adiponectin enhances Th1 differentiation via activation of the p38-STAT4-T-bet axis. This suggests that adiponectin can have a proinflammatory role in isolated macrophages and T-cells, confirming that adiponectin induces a limited spectrum of inflammatory activation, probably to make these cells less sensitive or reactive to more proinflammatory stimuli. ${ }^{129}$

\section{Inhibition of smooth muscle proliferation}

Rapid multiplication and migration of vascular SMCs toward the intima during development and progression of vascular lesions contribute to intimal thickening of the arteries and development of atherosclerosis. Such proliferation and migration in human aortic SMCs is inhibited by adiponectin. Adiponectin blocks this by inhibiting several atherogenic growth factors, including platelet-derived growth factor-BB, basic fibroblast growth factor, and heparin-binding epidermal 
growth factor. ${ }^{130,131}$ Oligomerization of adiponectin, which is reliant on interaction with these growth factors, can block binding to their respective cell membrane receptors. ${ }^{130}$ The clear findings by adiponectin-deficient mice, as compared with wild-type controls, showed an increased proliferation of vascular SMCs and neointimal thickening after mechanical injury. ${ }^{132}$ It was concluded that adiponectin can be detected by immunohistochemistry only in the walls of the injured vessels, ${ }^{133}$ suggesting a role in protection against the development of atherogenic vascular changes.

Adenovirus-mediated expression of adiponectin in mechanical balloon-injured arteries of adiponectin-deficient mice decreased the degree of neointimal proliferation, ${ }^{63}$ suggesting that therapeutically increasing plasma adiponectin might be beneficial for prevention of vascular restenosis after angioplasty.

\section{Endothelial construction and angiogenesis}

Impaired endothelial repair is a feature of vascular disease and heralds the start of atherosclerotic progression. Endothelial progenitor cells (EPCs) contribute critically to endothelial repair next to vascular injury. ${ }^{134}$ Dysfunction and/or low numbers of EPCs are associated with impaired endothelial function. ${ }^{135}$ Clinical and animal studies in subjects with coronary heart disease report a positive correlation between circulating levels of adiponectin and numbers of EPCs. ${ }^{79}$ Adiponectin increases the number and function of EPCs and promotes endothelial repair and angiogenesis . ${ }^{136,137}$

The angiogenic repair of ischemic hind limb, as estimated by laser Doppler flow method, and impaired capillary density analysis, was impaired in adiponectin-knockout mice. These were reversed by adenovirus-mediated addition of adiponectin. ${ }^{79}$ Almost all steps in endothelial repair of EPCs are modulated by adiponectin; these steps consist of mobilization of EPCs progenitors from the bone marrow or spleen into the blood circulation, recruitment and adhesion of EPCs to the injured endothelium, their differentiation to EPCs, and creation of EPCs tube-like structure. ${ }^{136,137}$

In diabetic mice, treatment with cobalt protoporphyrin, an inducer of heme oxygenase-1 (an antioxidant), leads to accelerated vascular repair by improving the function of EPCs as a result of upregulation of adiponectin. ${ }^{138}$ This evidence highlights the importance of adiponectin in the prevention of atherosclerotic progression by endothelial renovation and angiogenesis.

In $d b / d b$ diabetic mice without adiponectin, rosiglitazone (a PPAR- $\gamma$ agonist from the thiazolidinedione class of antidiabetic drugs) increased circulating EPC numbers and endothelial repair. More rapid impairment of reendothelialization has been reported after wire-induced carotid denudation in animal models of diabetes with insufficient adiponectin. ${ }^{139}$ Adiponectin prevents the impact of high glucose levels on stimulation of senescence in EPCs by decreasing the expression of p16 INK4A, a senescence marker that serves as a key mediator of the aging process in stem cells, in human peripheral blood, and in mouse bone marrow. ${ }^{140}$ Another reported importance of adiponectin is marked reduction of intracellular ROS accumulation and activation of p38 mitogen-activated protein kinase. ${ }^{139}$

The activity of adiponectin in vascular recruitment of EPCs requires activation of AMP kinase. ${ }^{80,133}$ Involvement of the endothelial phosphoinositide 3-kinase/ Akt and AMP kinase pathways is thought to interfere with adiponectin-induced angiogenesis. ${ }^{80}$ Clinical and animal studies have demonstrated the antioxidant properties of adiponectin. ${ }^{108,141-143}$ Circulating adiponectin in humans is in inverse association with certain markers of oxidative stress, including 8-epi-prostaglandin F2 $\alpha{ }^{141}$

Adiponectin decreases accumulation of intracellular ROS in conditions caused by high glucose, such as diabetes. In this way, adiponectin can deal with diabetes-induced damage of EPC function through activation of AMP kinase, inhibiting p38 MAP kinase, and decreasing expression of p16INK4A (a senescence marker). ${ }^{137}$ Because of eNOS' promoting effect on EPCs recruitment, adiponectin is necessary to repair endothelial cells. Adiponectin protects against EPC dysfunction in diabetic patients by enhancing eNOS production and signaling. ${ }^{144}$

Globular adiponectin significantly increased endothelial cell proliferation, in vitro migration, and angiogenesis by the AMP kinase/Akt pathways through increased expression of MMP-2, MMP-9 and vascular endothelial growth factor. ${ }^{145}$ The effect of globular adiponectin on vascular endothelial growth factor appears to be mediated by AdipoR1, while the effect on MMP-2 and MMP-9 is mediated by AdipoR1 and AdipoR2. Further, globular adiponectin decreased glucose levels and CRP-induced angiogenesis in human microvascular endothelial cells, with a concomitant reduction in MMP-2, MMP-9, and vascular endothelial growth factor. ${ }^{145}$

\section{Antiatherosclerotic effects of adiponectin}

Preclinical studies ${ }^{146}$ and animal models have demonstrated the importance of adiponectin in inhibition of atherogenesis..$^{40,67,114}$ High levels of plasma adiponectin 
decrease atherosclerotic plaque formation in apoE-deficient mice. ${ }^{37,67}$ Without adiponectin, the inhibitory effects of PPAR- $\gamma$ agonists on atherogenesis are lost. ${ }^{147}$ In vitro studies have usually used high doses of adiponectin due to its low level of bioactivity and the impact of contaminants that could influence this activity; however, given the antiatherosclerotic actions of adiponectin on almost all types of vascular cells as discussed above, the role of adiponectin in human atherogenesis is still debated. Despite globular adiponectin appearing to be responsible for most of the biological effects of adiponectin and its frequent use in in vitro studies, there is still no evidence of the existence of this form of adiponectin in the peripheral circulation in humans. Inconsistent results have been reported from studies using adiponectin produced by Escherichia coli. ${ }^{146}$

While genetic manipulation of adiponectin levels has yielded more reliable results, in a recent paper the Scherer's research group crossed adiponectin knockout mice $\left(A d n^{-/-}\right)$ into the LDL receptor-null mice or mice with chronically hyperadiponectinemia into apoE-null mouse models. In this study, circulating adiponectin levels were not correlated with inhibition of atherogenesis. Regardless of the type of diet used in these animal models, circulating adiponectin levels had no effect on plaque size in the aortic root, cholesterol accumulation in the aorta, and plaque morphology. ${ }^{148}$ These results are different from earlier reports obtained in an $A p o E^{-/-}$mouse model, which could be due to the use of different experimental paradigms, different forms of adiponectin, and different types of diet. ${ }^{149}$ Lack of a phenotype in gain/loss-of-function studies in animal models suggests that adiponectin is not involved in the advanced stages of plaque progression. ${ }^{148}$ These data indicate that adiponectin has complex and multifaceted actions in the cardiovascular system. Since mice are generally resistant to plaque rupture and myocardial infarction, there is still a need for more functional causation studies in humans.

\section{Antithrombotic effect of adiponectin}

Platelet activation plays a central role in the progression of atherosclerosis and plaque rupture. Inhibition of platelet aggregation has been suggested to prevent arterial thrombosis. ${ }^{150} \mathrm{~A}$ clinical study has demonstrated that the plasma adiponectin level was negatively associated with platelet activation independent of other risk factors. ${ }^{151}$ Platelet aggregation and enhanced thrombus formation on a type I collagen-coated surface have been demonstrated in platelet cells harvested from adiponectin-deficient mice and humans. ${ }^{152}$ Recombinant adiponectin repressed the enhanced platelet aggregation. Further, AdipoRs were found to be expressed in human platelets and in a megakaryocytic cell line. ${ }^{153}$ While platelet counts or coagulation factors were not significantly different between wild-type and adiponectin knockout mice, adiponectin knockout mice showed accelerated thrombus formation upon carotid arterial injury with a He-Ne laser, and adenovirus-mediated expression of adiponectin reversed these changes. ${ }^{152}$ Consequently, adiponectin may serve as an endogenous antithrombotic factor. ${ }^{152}$ The inhibitory effect of adiponectin on thrombosis can be attributed to its ability to stimulate production of endothelial NO, as discussed above.

\section{Therapeutic interventions and conclusion}

As discussed here, a number of studies have reported an important role of adiponectin in the vasculature via various pathways. Therefore, therapeutic approaches that increase adiponectin levels or tissue sensitivity could lead to useful strategies for the prevention or treatment of adiponectinrelated vascular disorders (Figure 4).

Although direct use of exogenous adiponectin is successful in ameliorating CVD in animals, this becomes difficult in humans because of the high circulating levels needed, its multimeric conformations, and its moderately short half-life. Also, as medications undergo extensive posttranslational modification, therefore extensive posttranslational medicine wanted them for action. Therapeutic interventions to increase endogenous adiponectin levels are one potential option for safely treating cardiovascular pathophysiology. In some conditions, such as lipodystrophy in individuals with human immunodeficiency virus, hypoadiponectinemia is a metabolic marker of subclinical cardiac disease, hence interventions that increase adiponectin can be useful in the treatment or control of the associated damage. ${ }^{154}$ Nutraceutical compounds, lifestyle changes, and several pharmacological drugs have been shown to enhance plasma adiponectin levels. ${ }^{6}$ Exercise (moderate aerobic training) and long-term weight loss by either gastric bypass surgery or calorie control increase plasma adiponectin levels in overweight/ obese or diabetic subjects. ${ }^{155-157}$ Further, weight reduction selectively enhances blood levels of HMW oligomeric adiponectin. ${ }^{158-161}$ These results suggest that at least part of the benefits of lifestyle intervention for cardiovascular health is mediated by adiponectin. In animals and humans with or without diabetes, a large number of nutraceutical products have been demonstrated to have beneficial effects 


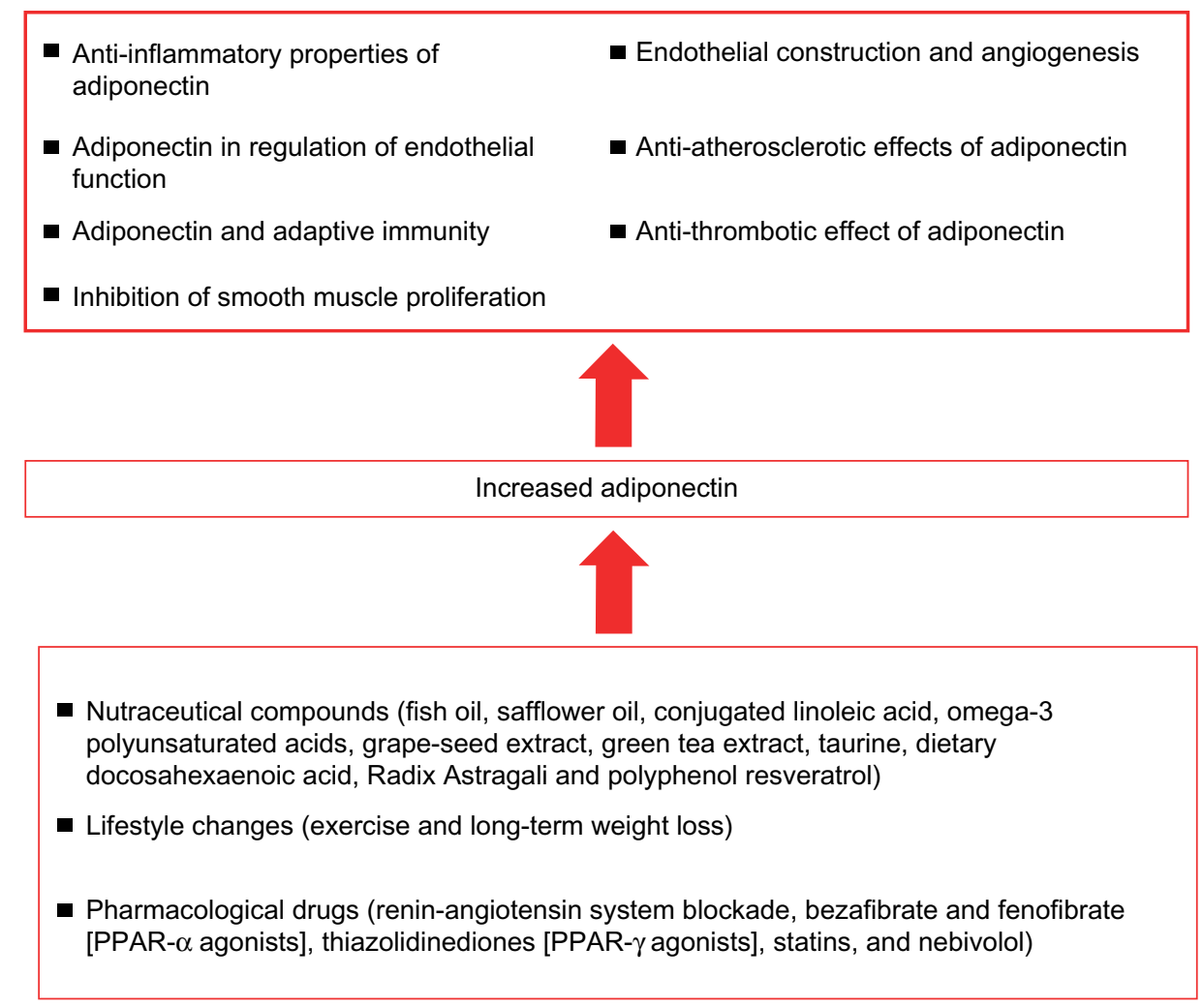

Figure 4 Summary of the cardioprotective effects and therapeutic interventions for enhancing adiponectin.

Abbreviation: PPAR, peroxisome proliferator-activated receptor.

on cardiovascular health by increasing the production of endogenous adiponectin. These including fish oil ${ }^{162}$ safflower oil, ${ }^{163}$ conjugated linoleic acid, ${ }^{164}$ omega-3 polyunsaturated acids, ${ }^{165}$ grape seed extract, ${ }^{166}$ green tea extract, ${ }^{14,167}$ taurine, ${ }^{168}$ dietary docosahexaenoic acid, ${ }^{169}$ Radix Astragali, ${ }^{170}$ aqueous humor, and the polyphenol resveratrol. ${ }^{171}$ Some pharmacological agents, including renin-angiotensin system blockers, PPAR- $\alpha$ agonists (bezafibrate and fenofibrate), PPAR- $\gamma$ agonists (thiazolidinediones), statins, and nebivolol have all been shown to increase plasma adiponectin levels.

Thiazolidinediones (pioglitazone and rosiglitazone, both PPAR- $\gamma$ agonists) elevate circulating adiponectin levels, especially HMW adiponectin, from adipocytes in both humans and rodents by increasing adiponectin gene expression. ${ }^{147,172-176}$ Due to some of the side effects of thiazolidinediones, including weight gain, fluid retention, and anemia, ${ }^{177}$ using rosiglitazone poses a cardiac threat. A meta-analysis of controlled clinical trials reported that rosiglitazone, compared with placebo or standard drugs for diabetes, significantly increased the risk of myocardial infarction. ${ }^{178}$ In contrast, adiponectin has cardioprotective activity. Therefore, using certain pharmacological agents, we can avoid these harmful effects of thiazolidinediones by selectively increasing plasma adiponectin levels.
The renin-angiotensin system is critical in the regulation of blood pressure. Enhanced angiotensin II in obesity is an important cause of insulin resistance, hypertension, and CVD. Circulating adiponectin can be increased by use of pharmacological inhibitors of the renin-angiotensin system, such as angiotensin-converting enzyme inhibitors and angiotensin II receptor blockers. These inhibitors are widely used in cardiology due to their ability to reduce blood pressure and protect the heart, as well as their antidiabetic activity. ${ }^{179,180}$ However, further studies are needed to determine whether or not some of these therapeutic effects are mediated by adiponectin.

There are some clinical data showing that losartan used alone or in combination with statins (in particular simvastatin) increases circulating adiponectin levels in hypertensive patients. ${ }^{181}$ However, some of the findings in these studies are inconsistent, indicating a need for further studies. Also, some recent findings show a change in the activity of adiponectin in relation to CVD risk factors in patients with rheumatoid arthritis, suggesting the importance of considering the health status of subjects before attempting adiponectin-enhancing interventions. ${ }^{33}$ Because of extremely high circulating levels of adiponectin, it has been proposed that altering the ratio of circulating adiponectin to HMW forms would be a more advantageous 
therapeutic approach than increasing total levels. ${ }^{182,183}$ Because circulating concentrations of globular adiponectin are very low, some investigators have suggested that the in vivo effects of globular adiponectin are not important. However, the current evidence shows that the bioactivity of globular adiponectin is greater than that of full-length adiponectin. Methods to enhance proteolytic cleavage of full-length adiponectin to globular adiponectin may serve as a potential therapeutic approach for enhancing the bioactivity of adiponectin. ${ }^{182,184}$ Additional research on the role of adiponectin as a therapeutic agent may lead to the development of an additional safe intervention to help decrease the epidemic of vascular disease.

\section{Disclosure}

The authors report no conflicts of interest in this work.

\section{References}

1. Arefhosseini SR, Edwards CA, Malkova D, Higgins S. Effect of advice to increase carbohydrate and reduce fat intake on dietary profile and plasma lipid concentrations in healthy postmenopausal women. Ann Nutr Metab. 2009;54(2):138-144.

2. Attar MJ, Mohammadi S, Karimi M, et al. Association of adiponectin with dietary factors and cardiovascular risk factors in type 2 diabetes mellitus patients. Diabetes Metab Syndr. 2013;7(1):3-7.

3. Mohammadi S, Hosseinzadeh-Attar MJ, Hosseinnezhad A, et al. Compare the effects of different visfatin concentration on cardiovascular risk factors, adiponectin and insulin resistance in patients with T2DM. Diabetes Metab Syndr. 2011;5(2):71-75.

4. Tilg H, Moschen AR. Adipocytokines: mediators linking adipose tissue, inflammation and immunity. Nat Rev Immunol. 2006;6(10): $772-783$.

5. Zhang P, Wang Y, Fan Y, Tang Z, Wang N. Overexpression of adiponectin receptors potentiates the antiinflammatory action of subeffective dose of globular adiponectin in vascular endothelial cells. Arterioscler Thromb Vasc Biol. 2009;29(1):67-74.

6. Zhu W, Cheng K, Vanhoutte P, Lam K, Xu A. Vascular effects of adiponectin: molecular mechanisms and potential therapeutic intervention. Clin Sci. 2008;114:361-374.

7. Kadowaki T, Yamauchi T, Kubota N, Hara K, Ueki K, Tobe K. Adiponectin and adiponectin receptors in insulin resistance, diabetes, and the metabolic syndrome. J Clin Invest. 2006;116(7): 1784-1792.

8. Coppola A, Marfella R, Coppola L, et al. Effect of weight loss on coronary circulation and adiponectin levels in obese women. Int J Cardiol. 2009;134(3):414-416.

9. Maeda K, Okubo K, Shimomura I, Funahashi T, Matsuzawa Y, Matsubara K. cDNA cloning and expression of a novel adipose specific collagen-like factor, apM1 (AdiPoseMost abundant Gene transcript 1). Biochem Biophys Res Commun. 1996;221(2):286-289.

10. Nakano Y, Tobe T, Choi-Miura N-H, Mazda T, Tomita M. Isolation and characterization of GBP28, a novel gelatin-binding protein purified from human plasma. J Biochem. 1996;120(4): 803-812.

11. Scherer PE, Williams S, Fogliano M, Baldini G, Lodish HF. A novel serum protein similar to $\mathrm{C} 1 \mathrm{q}$, produced exclusively in adipocytes. J Biol Chem. 1995;270(45):26746-26749.

12. Hu E, Liang P, Spiegelman BM. AdipoQ is a novel adipose-specific gene dysregulated in obesity. J Biol Chem.1996;271(18):10697-10703.
13. Frystyk J, Berne C, Berglund L, Jensevik K, Flyvbjerg A, Zethelius B. Serum adiponectin is a predictor of coronary heart disease: a populationbased 10-year follow-up study in elderly men. J Clin Endocrinol Metab. 2007;92(2):571-576.

14. Mohammadi S, Hosseinzadeh M, Karimi M, et al. The effects of green tea extract on serum adiponectin concentration and insulin resistance in patients with type 2 diabetes mellitus. J Zanjan Univ Med Sci. 2010;70(44):5.

15. Ukkola O, Santaniemi M. Adiponectin: a link between excess adiposity and associated comorbidities? J Mol Med. 2002;80(11):696-702.

16. Diez JJ, Iglesias P. The role of the novel adipocyte-derived hormone adiponectin in human disease. Eur J Endocrinol. 2003;148(3):293-300.

17. Shapiro L, Scherer PE. The crystal structure of a complement-1q family protein suggests an evolutionary link to tumor necrosis factor. Curr Biol. 1998;8(6):335-340.

18. Taso T, Murrey H, Hug C, Lee D, Lodish H. Oligomerization statedependent activation of NF-kB signaling pathway by Acrp30. J Biol Chem. 2002;277:29359-29362.

19. Pajvani UB, Du X, Combs TP, et al. Structure-function studies of the adipocyte-secreted hormone Acrp30/adiponectin: implications for metabolic regulation and bioactivity. J Biol Chem. 2003;278(11):9073-9085.

20. Hattori Y, Hattori S, Akimoto K, et al. Globular adiponectin activates nuclear factor- $\kappa \mathrm{B}$ and activating protein-1 and enhances angiotensin II-induced proliferation in cardiac fibroblasts. Diabetes. 2007;56(3):804-808.

21. Suzuki S, Wilson-Kubalek EM, Wert D, Tsao T-S, Lee DH. The oligomeric structure of high molecular weight adiponectin. FEBS Lett. 2007;581(5):809-814.

22. Halberg N, Schraw TD, Wang ZV, et al. Systemic fate of the adipocytederived factor adiponectin. Diabetes. 2009;58(9):1961-1970.

23. Pajvani UB, Hawkins M, Combs TP, et al. Complex distribution, not absolute amount of adiponectin, correlates with thiazolidinedionemediated improvement in insulin sensitivity. J Biol Chem. 2004;279(13): 12152-12162.

24. Tonelli J, Li W, Kishore P, et al. Mechanisms of early insulinsensitizing effects of thiazolidinediones in type 2 diabetes. Diabetes. 2004;53(6):1621-1629.

25. Tsao T-S, Tomas E, Murrey HE, et al. Role of disulfide bonds in Acrp30/adiponectin structure and signaling specificity different oligomers active different signal transduction pathways. J Biol Chem. 2003;278(50):50810-50817.

26. Arita Y, Kihara S, Ouchi N, et al. Paradoxical decrease of an adiposespecific protein, adiponectin, in obesity. Biochem Biophys Res Commun. 1999;257(1):79-83.

27. Hotta K, Funahashi T, Arita Y, et al. Plasma concentrations of a novel, adipose-specific protein, adiponectin, in type 2 diabetic patients. Arterioscler Thromb Vasc Biol. 2000;20(6):1595-1599.

28. Wannamethee SG, Welsh P, Whincup PH, et al. High adiponectin and increased risk of cardiovascular disease and mortality in asymptomatic older men: does NT-proBNP help to explain this association? Eur $J$ Cardiovasc Prev Rehabil. 2011;18(1):65-71.

29. Pischon T, Hu FB, Girman CJ, et al. Plasma total and high molecular weight adiponectin levels and risk of coronary heart disease in women. Atherosclerosis. 2011;219(1):322-329.

30. Ho DY, Cook NR, Britton KA, et al. High-molecular-weight and total adiponectin levels and incident symptomatic peripheral artery disease in women a prospective investigation. Circulation. 2011;124(21):2303-2311.

31. Kizer JR, Benkeser D, ArnoldAM, et al. Total and high-molecular-weight adiponectin and risk of coronary heart disease and ischemic stroke in older adults. J Clin Endocrinol Metab. 2012;98(1):255-263.

32. Frommer KW, Zimmermann B, Meier FM, et al. Adiponectin-mediated changes in effector cells involved in the pathophysiology of rheumatoid arthritis. Arthritis Rheum. 2010;62(10):2886-2899.

33. Dessein PH, Norton GR, Badenhorst M, Woodiwiss AJ, Solomon A. Rheumatoid arthritis impacts on the independent relationships between circulating adiponectin concentrations and cardiovascular metabolic risk. Mediators Inflamm. 2013;2013:461849. 
34. Trujillo M, Hanif W, Barnett A, McTernan P, Scherer P, Kumar S. Serum high molecular weight complex of adiponectin correlates better with glucose tolerance than total serum adiponectin in Indo-Asian males. Diabetologia. 2005;48(6):1084-1087.

35. Aso Y, Yamamoto R, Wakabayashi S, et al. Comparison of serum high-molecular weight (HMW) adiponectin with total adiponectin concentrations in type 2 diabetic patients with coronary artery disease using a novel enzyme-linked immunosorbent assay to detect HMW adiponectin. Diabetes. 2006;55(7):1954-1960.

36. Welsh P, Whincup P, Sattar N, Wannamethee G. Elevated adiponectin and increased risk of cardiovascular disease and mortality in asymptomatic older men: does NT-proBNP explain the paradox? Atherosclerosis. 2010;213(1):e3.

37. Yamauchi T, Kamon J, Ito Y, et al. Cloning of adiponectin receptors that mediate antidiabetic metabolic effects. Nature. 2003;423(6941) $762-769$.

38. Yamauchi T, Nio Y, Maki T, et al. Targeted disruption of AdipoR1 and AdipoR2 causes abrogation of adiponectin binding and metabolic actions. Nat Med. 2007;13(3):332-339.

39. Yoon MJ, Lee GY, Chung J-J, Ahn YH, Hong SH, Kim JB. Adiponectin increases fatty acid oxidation in skeletal muscle cells by sequential activation of AMP-activated protein kinase, p38 mitogen-activated protein kinase, and peroxisome proliferator-activated receptor $\alpha$. Diabetes 2006;55(9):2562-2570.

40. Yamauchi T, Kamon J, Minokoshi Y, et al. Adiponectin stimulates glucose utilization and fatty-acid oxidation by activating AMP-activated protein kinase. Nat Med. 2002;8(11):1288-1295.

41. Cheng KK, Lam KS, Wang Y, et al. Adiponectin-induced endothelial nitric oxide synthase activation and nitric oxide production are mediated by APPL1 in endothelial cells. Diabetes. 2007;56(5):1387-1394.

42. Mao X, Kikani CK, Riojas RA, et al. APPL1 binds to adiponectin receptors and mediates adiponectin signalling and function. Nat Cell Biol. 2006;8(5):516-523.

43. Bjursell M, Ahnmark A, Bohlooly-YM, et al. Opposing effects of adiponectin receptors 1 and 2 on energy metabolism. Diabetes. 2007;56(3):583-593.

44. Liu Y, Michael MD, Kash S, et al. Deficiency of adiponectin receptor 2 reduces diet-induced insulin resistance but promotes type 2 diabetes Endocrinology. 2007;148(2):683-692.

45. Ranscht B, Bronner-Fraser M. T-cadherin expression alternates with migrating neural crest cells in the trunk of the avian embryo. Development. 1991;111(1):15-22.

46. Hug C, Wang J, Ahmad NS, Bogan JS, Tsao T-S, Lodish HF. T-cadherin is a receptor for hexameric and high-molecular-weight forms of Acrp30/ adiponectin. Proc Natl Acad Sci USA. 2004;101(28):10308-10313.

47. Joshi MB, Philippova M, Ivanov D, Allenspach R, Erne P, Resink TJ. T-cadherin protects endothelial cells from oxidative stress-induced apoptosis. FASEB J. 2005;19(12):1737-1739.

48. Takeuchi T, Adachi Y, Ohtsuki Y, Furihata M. Adiponectin receptors, with special focus on the role of the third receptor, T-cadherin, in vascular disease. Med Mol Morphol. 2007;40(3):115-120.

49. Parker-Duffen JL, Nakamura K, Silver M, et al. T-cadherin is essential for adiponectin-mediated revascularization. $J$ Biol Chem 2013;288(34):24886-24897.

50. Ouwens DM, Sell H, Greulich S, Eckel J. The role of epicardial and perivascular adipose tissue in the pathophysiology of cardiovascular disease. J Cell Mol Med. 2010;14(9):2223-2234.

51. Mazurek T, Zhang L, Zalewski A, et al. Human epicardial adipose tissue is a source of inflammatory mediators. Circulation. 2003;108(20):2460-2466.

52. Iacobellis G, Corradi D, Sharma AM. Epicardial adipose tissue: anatomic, biomolecular and clinical relationships with the heart. Nat Clin Pract Cardiovasc Med. 2005;2(10):536-543.

53. Larson-Meyer DE, Heilbronn LK, Redman LM, et al. Effect of calorie restriction with or without exercise on insulin sensitivity, $\beta$-cell function, fat cell size, and ectopic lipid in overweight subjects. Diabetes Care. 2006;29(6):1337-1344.
54. De Larochellière E, Côté J, Gilbert G, et al. Visceral/epicardial adiposity in nonobese and apparently healthy young adults: association with the cardiometabolic profile. Atherosclerosis. 2014;234(1):23-29.

55. Bambace C, Telesca M, Zoico E, et al. Adiponectin gene expression and adipocyte diameter: a comparison between epicardial and subcutaneous adipose tissue in men. Cardiovasc Pathol. 2011;20(5):e153-e156.

56. McKenney ML, Schultz KA, Boyd JH, et al. Epicardial adipose excision slows the progression of porcine coronary atherosclerosis. J Cardiothorac Surg. 2014;9(1):1-11.

57. Zhang Y, Zitsman JL, Hou J, et al. Fat cell size and adipokine expression in relation to gender, depot, and metabolic risk factors in morbidly obese adolescents. Obesity (Silver Spring). 2014;22(3):691-697.

58. Trujillo M, Scherer P. Adiponectin - journey from an adipocyte secretory protein to biomarker of the metabolic syndrome. J Intern Med. 2005;257(2):167-175.

59. Lam KS, Xu A. Adiponectin: protection of the endothelium. Curr Diab Rep. 2005;5(4):254-259.

60. Okui H, Hamasaki S, Ishida $\mathrm{S}$, et al. Adiponectin is a better predictor of endothelial function of the coronary artery than HOMA-R, body mass index, immunoreactive insulin, or triglycerides. Int $J$ Cardiol. 2008;126(1):53-61.

61. Torigoe M, Matsui H, OgawaY, et al. Impact of the high-molecular-weight form of adiponectin on endothelial function in healthy young men. Clin Endocrinol. 2007;67(2):276-281.

62. Szmitko PE, Teoh H, Stewart DJ, Verma S. Adiponectin and cardiovascular disease: state of the art? Am J Physiol Heart Circ Physiol. 2007;292(4):H1655-H1663.

63. Matsuda M, Shimomura I, Sata M, et al. Role of adiponectin in preventing vascular stenosis: the missing link of adipo-vascular axis. $J$ Biol Chem. 2002;277(40):37487-37491.

64. Kubota N, Terauchi Y, Kubota T, et al. Pioglitazone ameliorates insulin resistance and diabetes by both adiponectin-dependent and -independent pathways. J Biol Chem. 2006;281(13):8748-8755.

65. Ouchi N, Ohishi M, Kihara S, et al. Association of hypoadiponectinemia with impaired vasoreactivity. Hypertension. 2003;42(3):231-234.

66. Shimabukuro M, Higa N, Asahi T, et al. Hypoadiponectinemia is closely linked to endothelial dysfunction in man. J Clin Endocrinol Metab. 2003;88(7):3236-3240.

67. Okamoto Y, Kihara S, Ouchi N, et al. Adiponectin reduces atherosclerosis in apolipoprotein E-deficient mice. Circulation. 2002;106(22):2767-2770.

68. Ouchi N, Walsh K. Adiponectin as an anti-inflammatory factor. Clin Chim Acta. 2007;380(1):24-30.

69. Libby P, Okamoto Y, Rocha VZ, Folco E. Inflammation in atherosclerosis. Circ J. 2010;74:213-220.

70. Ouchi N, Walsh K. A novel role for adiponectin in the regulation of inflammation. Arterioscler Thromb Vasc Biol. 2008;28(7): 1219-1221.

71. Ridker PM. High-sensitivity C-reactive protein and cardiovascular risk: rationale for screening and primary prevention. Am J Cardiol. 2003;92(4):17-22.

72. Laaksonen D, Niskanen L, Nyyssönen K, et al. C-reactive protein and the development of the metabolic syndrome and diabetes in middle-aged men. Diabetologia. 2004;47(8):1403-1410.

73. Yudkin JS, Stehouwer C, Emeis J, Coppack S. C-reactive protein in healthy subjects: associations with obesity, insulin resistance, and endothelial dysfunction a potential role for cytokines originating from adipose tissue? Arterioscler Thromb Vasc Biol. 1999;19(4):972-978.

74. Paffen E, Moniek P. C-reactive protein in atherosclerosis: a causal factor? Cardiovasc Res. 2006;71(1):30-39.

75. Venugopal SK, Devaraj S, Jialal I. Macrophage conditioned medium induces the expression of C-reactive protein in human aortic endothelial cells: potential for paracrine/autocrine effects. Am J Pathol. 2005;166(4):1265-1271.

76. Ouchi N, Kihara S, Arita Y, et al. Adiponectin, an adipocyte-derived plasma protein, inhibits endothelial NF- $\mathrm{KB}$ signaling through a cAMPdependent pathway. Circulation. 2000;102(11):1296-1301. 
77. Ouchi N, Kihara S, Arita Y, et al. Novel modulator for endothelial adhesion molecules adipocyte-derived plasma protein adiponectin. Circulation. 1999;100(25):2473-2476.

78. Kobashi C, Urakaze M, Kishida M, et al. Adiponectin inhibits endothelial synthesis of interleukin-8. Circ Res. 2005;97(12):1245-1252.

79. Shibata R, Sato K, Pimentel DR, et al. Adiponectin protects against myocardial ischemia-reperfusion injury through AMPK-and COX-2dependent mechanisms. Nat Med. 2005;11(10):1096-1103.

80. Ouchi N, Kobayashi H, Kihara S, et al. Adiponectin stimulates angiogenesis by promoting cross-talk between AMP-activated protein kinase and Akt signaling in endothelial cells. J Biol Chem. 2004;279(2):1304-1309.

81. Cacicedo JM, Yagihashi N, Keaney JF Jr, Ruderman NB, Ido Y. AMPK inhibits fatty acid-induced increases in NF- $\kappa B$ transactivation in cultured human umbilical vein endothelial cells. Biochem Biophys Res Commun. 2004;324(4):1204-1209.

82. Libby P, Ridker PM, Maseri A. Inflammation and atherosclerosis. Circulation. 2002;105(9):1135-1143.

83. Ouchi N, Kihara S, Arita Y, et al. Adipocyte-derived plasma protein, adiponectin, suppresses lipid accumulation and class A scavenger receptor expression in human monocyte-derived macrophages. Circulation. 2001;103(8):1057-1063.

84. Ohashi K, Parker JL, Ouchi N, et al. Adiponectin promotes macrophage polarization toward an anti-inflammatory phenotype. J Biol Chem. 2010;285(9):6153-6160.

85. Takemura Y, Ouchi N, Shibata R, et al. Adiponectin modulates inflammatory reactions via calreticulin receptor-dependent clearance of early apoptotic bodies. J Clin Invest. 2007;117(2):375-386.

86. Weigert J, Neumeier M, Wanninger J, et al. Reduced response to adiponectin and lower abundance of adiponectin receptor proteins in type 2 diabetic monocytes. FEBS Lett. 2008;582(12):1777-1782.

87. Kollias A, Tsiotra PC, Ikonomidis I, et al. Adiponectin levels and expression of adiponectin receptors in isolated monocytes from overweight patients with coronary artery disease. Cardiovasc Diabetol. 2011;10(14):14-26.

88. Wolf AM, Wolf D, Rumpold H, Enrich B, Tilg H. Adiponectin induces the anti-inflammatory cytokines IL-10 and IL-1RA in human leukocytes. Biochem Biophys Res Commun. 2004;323(2):630-635.

89. Kumada M, Kihara S, Ouchi N, et al. Adiponectin specifically increased tissue inhibitor of metalloproteinase-1 through interleukin-10 expression in human macrophages. Circulation. 2004;109(17):2046-2049.

90. Cheng M, Hashmi S, Mao X, Zeng QT. Relationships of adiponectin and matrix metalloproteinase- 9 to tissue inhibitor of metalloproteinase-1 ratio with coronary plaque morphology in patients with acute coronary syndrome. Can J Cardiol. 2008;24(5):385-390.

91. Xu A, Tso AW, Cheung BM, et al. Circulating adipocyte-fatty acid binding protein levels predict the development of the metabolic syndrome: a 5-year prospective study. Circulation. 2007;115(12):1537-1543.

92. Wang Y, Lam KS, Kraegen EW, et al. Lipocalin-2 is an inflammatory marker closely associated with obesity, insulin resistance, and hyperglycemia in humans. Clin Chem. 2007;53(1):34-41.

93. Furukawa K, Hori M, Ouchi N, et al. Adiponectin down-regulates acyl-coenzyme A: cholesterol acyltransferase-1 in cultured human monocyte-derived macrophages. Biochem Biophys Res Commun. 2004;317(3):831-836.

94. Tian L, Luo N, Klein RL, Chung BH, Garvey WT, Fu Y. Adiponectin reduces lipid accumulation in macrophage foam cells. Atherosclerosis. 2009;202(1):152-161.

95. Jenke A, Wilk S, Poller W, et al. Adiponectin protects against Toll-like receptor 4-mediated cardiac inflammation and injury. Cardiovasc Res. 2013;99(3):422-431.

96. Kumada M, Kihara S, Sumitsuji S, et al. Association of hypoadiponectinemia with coronary artery disease in men. Arterioscler Thromb Vasc Biol. 2003;23(1):85-89.
97. Diamant M, Tushuizen ME. The metabolic syndrome and endothelial dysfunction: common highway to type 2 diabetes and CVD? Curr Diab Rep. 2006;6(4):279-286.

98. Pischon T, Girman CJ, Hotamisligil GS, Rifai N, Hu FB, Rimm EB. Plasma adiponectin levels and risk of myocardial infarction in men. JAMA. 2004;291(14):1730-1737.

99. Chen H, Montagnani M, Funahashi T, Shimomura I, Quon MJ. Adiponectin stimulates production of nitric oxide in vascular endothelial cells. J Biol Chem. 2003;278(45):45021-45026.

100. Huang PL. Endothelial nitric oxide synthase and endothelial dysfunction. Curr Hypertens Rep. 2003;5(6):473-480.

101. Chen Z, Peng I-C, Sun W, et al. AMP-activated protein kinase functionally phosphorylates endothelial nitric oxide synthase Ser633. Circ Res. 2009;104(4):496-505.

102. Lin L-Y, Lin C-Y, Su T-C, Liau C-S. Angiotensin II-induced apoptosis in human endothelial cells is inhibited by adiponectin through restoration of the association between endothelial nitric oxide synthase and heat shock protein 90. FEBS Lett. 2004;574(1):106-110.

103. Xi W, Satoh H, Kase H, Suzuki K, Hattori Y. Stimulated HSP90 binding to eNOS and activation of the PI3-Akt pathway contribute to globular adiponectin-induced NO production: vasorelaxation in response to globular adiponectin. Biochem Biophys Res Commun. 2005;332(1):200-205.

104. Schmid PM, Resch M, Steege A, et al. Globular and full-length adiponectin induce NO-dependent vasodilation in resistance arteries of Zucker lean but not Zucker diabetic fatty rats. Am J Hypertens. 2011;24(3):270-277.

105. Tan $\mathrm{K}, \mathrm{Xu} \mathrm{A}$, Chow W, et al. Hypoadiponectinemia is associated with impaired endothelium-dependent vasodilation. J Clin Endocrinol Metab. 2004;89(2):765-769.

106. Schleicher E, Friess U. Oxidative stress, AGE, and atherosclerosis. Kidney Int. 2007;72:S17-S26.

107. Margaritis M, Antonopoulos AS, Digby J, et al. Interactions between vascular wall and perivascular adipose tissue reveal novel roles for adiponectin in the regulation of endothelial nitric oxide synthase function in human vessels. Circulation. 2013;127(22):2209-2221.

108. Ouedraogo R, Wu X, Xu S-Q, et al. Adiponectin suppression of highglucose-induced reactive oxygen species in vascular endothelial cells evidence for involvement of a cAMP signaling pathway. Diabetes. 2006;55(6):1840-1846.

109. Motoshima H, Wu X, Mahadev K, Goldstein BJ. Adiponectin suppresses proliferation and superoxide generation and enhances eNOS activity in endothelial cells treated with oxidized LDL. Biochem Biophys Res Commun. 2004;315(2):264-271.

110. Plant S, Shand B, Elder P, Scott R. Adiponectin attenuates endothelial dysfunction induced by oxidised low-density lipoproteins. Diab Vasc Dis Res. 2008;5(2):102-108.

111. Kim J-E, Song SE, Kim Y-W, et al. Adiponectin inhibits palmitateinduced apoptosis through suppression of reactive oxygen species in endothelial cells: involvement of cAMP/protein kinase A and AMPactivated protein kinase. J Endocrinol. 2010;207(1):35-44.

112. Cao Y, Tao L, Yuan Y, et al. Endothelial dysfunction in adiponectin deficiency and its mechanisms involved. J Mol Cell Cardiol. 2009;46(3):413-419.

113. Ding W, Zhang X, Huang $\mathrm{H}$, et al. Adiponectin protects rat myocardium against chronic intermittent hypoxia-induced injury via inhibition of endoplasmic reticulum stress. PLoS One. 2014;9(4):e94545.

114. Li C-J, Sun H-W, Zhu F-L, et al. Local adiponectin treatment reduces atherosclerotic plaque size in rabbits. $J$ Endocrinol. 2007; 193(1):137-145

115. Wu X, Mahadev K, Fuchsel L, Ouedraogo R, Xu S-Q, Goldstein BJ. Adiponectin suppresses I $\mathrm{B}$ kinase activation induced by tumor necrosis factor- $\alpha$ or high glucose in endothelial cells: role of cAMP and AMP kinase signaling. Am J Physiol Endocrinol Metab. 2007;293(6): E1836-E1844 
116. Kase H, Hattori Y, Jojima T, et al. Globular adiponectin induces adhesion molecule expression through the sphingosine kinase pathway in vascular endothelial cells. Life Sci. 2007;81(11):939-943.

117. Tsao T-S, Murrey HE, Hug C, Lee DH, Lodish HF. Oligomerization state-dependent activation of NF- $\mathrm{KB}$ signaling pathway by adipocyte complement-related protein of $30 \mathrm{kDa}$ (Acrp30). J Biol Chem. 2002;277(33):29359-29362.

118. Devaraj S, Torok N, Dasu MR, Samols D, Jialal I. Adiponectin decreases C-reactive protein synthesis and secretion from endothelial cells evidence for an adipose tissue-vascular loop. Arterioscler Thromb Vasc Biol. 2008;28(7):1368-1374.

119. Kobayashi H, Ouchi N, Kihara S, et al. Selective suppression of endothelial cell apoptosis by the high molecular weight form of adiponectin. Circ Res. 2004;94(4):e27-e31.

120. Xiao X, Dong Y, Zhong J, et al. Adiponectin protects endothelial cells from the damages induced by the intermittent high level of glucose. Endocrine. 2011;40(3):386-393.

121. Zhao H-y, Zhao M, Yi T-N, Zhang J. Globular adiponectin protects human umbilical vein endothelial cells against apoptosis through adiponectin receptor 1 /adenosine monophosphate-activated protein kinase pathway. Chin Med J (Engl). 2011;124(16):2540-2547.

122. Zhi Z, Pengfei Z, Xiaoyi T, Genshan M. Adiponectin ameliorates angiotensin II-induced vascular endothelial damage. Cell Stress Chaperones. 2014:19(5):705-713.

123. Mach F, Sauty A, Iarossi AS, et al. Differential expression of three T lymphocyte-activating CXC chemokines by human atheromaassociated cells. J Clin Invest. 1999;104(8):1041-1050.

124. Braunersreuther V, Mach F, Steffens S. The specific role of chemokines in atherosclerosis. Thrombos Haemost. 2007;97(5):714-721.

125. Michelsen KS, Doherty TM, Shah PK, Arditi M. TLR signaling: an emerging bridge from innate immunity to atherogenesis. J Immunol. 2004; 173(10):5901-5907.

126. Michelsen KS, Wong MH, Shah PK, et al. Lack of Toll-like receptor 4 or myeloid differentiation factor 88 reduces atherosclerosis and alters plaque phenotype in mice deficient in apolipoprotein E. Proc Natl Acad Sci U S A. 2004;101(29):10679-10684.

127. Shi H, Kokoeva MV, Inouye K, Tzameli I, Yin H, Flier JS. TLR4 links innate immunity and fatty acid-induced insulin resistance. J Clin Invest. 2006;116(11):3015-3025.

128. Wulster-Radcliffe MC,Ajuwon KM, Wang J, Christian JA, Spurlock ME. Adiponectin differentially regulates cytokines in porcine macrophages. Biochem Biophys Res Commun. 2004;316(3):924-929.

129. Cheng X, Folco EJ, Shimizu K, Libby P. Adiponectin induces proinflammatory programs in human macrophages and CD4+ T cells. J Biol Chem. 2012;287(44):36896-36904.

130. Wang Y, Lam KS, Xu JY, et al. Adiponectin inhibits cell proliferation by interacting with several growth factors in an oligomerizationdependent manner. J Biol Chem. 2005;280(18):18341-18347.

131. Arita Y, Kihara S, Ouchi N, et al. Adipocyte-derived plasma protein adiponectin acts as a platelet-derived growth factor-BBbinding protein and regulates growth factor-induced common postreceptor signal in vascular smooth muscle cell. Circulation. 2002;105(24):2893-2898.

132. Kubota N, Terauchi Y, Yamauchi T, et al. Disruption of adiponectin causes insulin resistance and neointimal formation. J Biol Chem. 2002;277(29):25863-25866.

133. Sambuceti G, Morbelli S, Vanella L, et al. Diabetes impairs the vascular recruitment of normal stem cells by oxidant damage, reversed by increases in pAMPK, heme oxygenase-1, and adiponectin. Stem Cells. 2009;27(2):399-407.

134. Szmitko PE, Fedak PW, Weisel RD, Stewart DJ, Kutryk MJ, Verma S. Endothelial progenitor cells: new hope for a broken heart. Circulation. 2003;107(24):3093-3100.

135. Fadini GP, Sartore S, Agostini C, Avogaro A. Significance of endothelial progenitor cells in subjects with diabetes. Diabetes Care. 2007;30(5):1305-1313.
136. Xu A, Wang Y, Lam KS, Vanhoutte PM. Vascular actions of adipokines: molecular mechanisms and therapeutic implications. Adv Pharmacol. 2010;60:229-255.

137. Zampetaki A, Kirton JP, Xu Q. Vascular repair by endothelial progenitor cells. Cardiovasc Res. 2008;78(3):413-421.

138. Li M, Kim DH, Tsenovoy PL, et al. Treatment of obese diabetic mice with a heme oxygenase inducer reduces visceral and subcutaneous adiposity, increases adiponectin levels, and improves insulin sensitivity and glucose tolerance. Diabetes. 2008;57(6):1526-1535

139. Chang J, Li Y, Huang Y, et al. Adiponectin prevents diabetic premature senescence of endothelial progenitor cells and promotes endothelial repair by suppressing the p38 MAP kinase/p16INK4A signaling pathway. Diabetes. 2010;59(11):2949-2959.

140. Janzen V, Forkert R, Fleming HE, et al. Stem-cell ageing modified by the cyclin-dependent kinase inhibitor p16INK4a. Nature. 2006;443(7110):421-426.

141. Katsuki A, Suematsu M, Gabazza EC, et al. Increased oxidative stress is associated with decreased circulating levels of adiponectin in Japanese metabolically obese, normal-weight men with normal glucose tolerance. Diabetes Res Clin Pract. 2006;73(3): 310-314.

142. Zhou M, Xu A, Tam PK, et al. Mitochondrial dysfunction contributes to the increased vulnerabilities of adiponectin knockout mice to liver injury. Hepatology. 2008;48(4):1087-1096.

143. Tao L, Gao E, Jiao X, et al. Adiponectin cardioprotection after myocar$\mathrm{dial}$ ischemia/reperfusion involves the reduction of oxidative/nitrative stress. Circulation. 2007;115(11):1408-1416.

144. Wegiel B, Gallo DJ, Raman KG, et al. Nitric oxide-dependent bone marrow progenitor mobilization by carbon monoxide enhances endothelial repair after vascular injury. Circulation. 2010;121(4): 537-548

145. Adya R, Tan BK, Chen J, Randeva HS. Protective actions of globular and full-length adiponectin on human endothelial cells: novel insights into adiponectin-induced angiogenesis. J Vasc Res. 2012;49(6):534-543.

146. Fantuzzi G. Adiponectin in inflammatory and immune-mediated diseases. Cytokine. 2013;64(1):1-10.

147. Hiuge-Shimizu A, Maeda N, Hirata A, et al. Dynamic changes of adiponectin and S100A8 levels by the selective peroxisome proliferatoractivated receptor- $\gamma$ agonist rivoglitazone. Arterioscler Thromb Vasc Biol. 2011;31(4):792-799.

148. Nawrocki AR, Hofmann SM, Teupser D, et al. Lack of association between adiponectin levels and atherosclerosis in mice. Arterioscler Thromb Vasc Biol. 2010;30(6):1159-1165.

149. Okamoto Y, Folco EJ, Minami M, et al. Adiponectin inhibits the production of CXC receptor 3 chemokine ligands in macrophages and reduces T-lymphocyte recruitment in atherogenesis. Circ Res. 2008;102(2):218-225

150. Wagner DD, Burger PC. Platelets in inflammation and thrombosis Arterioscler Thromb Vasc Biol. 2003;23(12):2131-2137.

151. Shoji T, Koyama H, Fukumoto S, et al. Platelet activation is associated with hypoadiponectinemia and carotid atherosclerosis. Atherosclerosis. 2006;188(1):190-195.

152. Kato H, Kashiwagi H, Shiraga M, et al. Adiponectin acts as an endogenous antithrombotic factor. Arterioscler Thromb Vasc Biol. 2006;26(1):224-230.

153. Liao Y, Takashima S, Maeda N, et al. Exacerbation of heart failure in adiponectin-deficient mice due to impaired regulation of AMPK and glucose metabolism. Cardiovasc Res. 2005;67(4):705-713.

154. Bezante GP, Briatore L, Rollando D, et al. Hypoadiponectinemia in lipodystrophic HIV individuals: a metabolic marker of subclinical cardiac damage. Nutr Metab Cardiovasc Dis. 2009;19(4):277-282.

155. Yang W-S, Lee W-J, Funahashi T, et al. Weight reduction increases plasma levels of an adipose-derived anti-inflammatory protein, adiponectin. J Clin Endocrinol Metab. 2001;86(8):3815-3819. 
156. Kriketos AD, Gan SK, Poynten AM, Furler SM, Chisholm DJ, Campbell LV. Exercise increases adiponectin levels and insulin sensitivity in humans. Diabetes Care. 2004;27(2):629-630.

157. Esposito K, Pontillo A, Di Palo C, et al. Effect of weight loss and lifestyle changes on vascular inflammatory markers in obese women: a randomized trial. JAMA. 2003;289(14):1799-1804.

158. Martos-Moreno GÁ, Barrios V, Martínez G, Hawkins F, Argente J. Effect of weight loss on high-molecular weight adiponectin in obese children. Obesity. 2010;18(12):2288-2294.

159. Cambuli VM, Musiu MC, Incani M, et al. Assessment of adiponectin and leptin as biomarkers of positive metabolic outcomes after lifestyle intervention in overweight and obese children. J Clin Endocrinol Metab. 2008;93(8):3051-3057.

160. Shinmura K, Tamaki K, Saito K, Nakano Y, Tobe T, Bolli R. Cardioprotective effects of short-term caloric restriction are mediated by adiponectin via activation of AMP-activated protein kinase. Circulation. 2007;116(24):2809-2817.

161. Kondo M, Shibata R, Miura R, et al. Caloric restriction stimulates revascularization in response to ischemia via adiponectin-mediated activation of endothelial nitric-oxide synthase. J Biol Chem. 2009;284(3):1718-1724.

162. Rossi AS, Lombardo YB, Lacorte J-M, et al. Dietary fish oil positively regulates plasma leptin and adiponectin levels in sucrose-fed, insulin-resistant rats. Am J Physiol Heart Circ Physiol. 2005;289(2):R486-R494.

163. Sekine S, Sasanuki S, Murano Y, Aoyama T, Takeuchi H. $\alpha$-linolenic acid-rich flaxseed oil ingestion increases plasma adiponectin level in rats. Int J Vitam Nutr Res. 2008;78(45):223-229.

164. Nagao K, Inoue N, Wang Y-M, Yanagita T. Conjugated linoleic acid enhances plasma adiponectin level and alleviates hyperinsulinemia and hypertension in Zucker diabetic fatty $(\mathrm{fa} / \mathrm{fa})$ rats. Biochem Biophys Res Commun. 2003;310(2):562-566.

165. Flachs P, Mohamed-Ali V, Horakova O, et al. Polyunsaturated fatty acids of marine origin induce adiponectin in mice fed a high-fat diet. Diabetologia. 2006;49(2):394-397.

166. Terra X, Montagut G, Bustos M, et al. Grape-seed procyanidins prevent low-grade inflammation by modulating cytokine expression in rats fed a high-fat diet. J Nutr Biochem. 2009;20(3):210-218.

167. Hsu C-H, Tsai T-H, Kao Y-H, Hwang K-C, Tseng T-Y, Chou P. Effect of green tea extract on obese women: a randomized, double-blind, placebo-controlled clinical trial. Clin Nutr. 2008;27(3):363-370.

168. Chen X, Sebastian BM, Tang H, et al. Taurine supplementation prevents ethanol-induced decrease in serum adiponectin and reduces hepatic steatosis in rats. Hepatology. 2009;49(5):1554-1562.

169. Lefils J, Géloën A, Vidal H, Lagarde M, Bernoud-Hubac N. Dietary DHA: time course of tissue uptake and effects on cytokine secretion in mice. Br J Nutr. 2010;104(09):1304-1312.
170. Xu A, Wang H, Hoo RL, et al. Selective elevation of adiponectin production by the natural compounds derived from a medicinal herb alleviates insulin resistance and glucose intolerance in obese mice. Endocrinology. 2009;150(2):625-633.

171. Wang A, Liu M, Liu X, et al. Up-regulation of adiponectin by resveratrol: the essential roles of the Akt/FOXO1 and AMP-activated protein kinase signaling pathways and DsbA-L. J Biol Chem. 2011;286(1):60-66.

172. Phillips SA, Kung J, Ciaraldi TP, et al. Selective regulation of cellular and secreted multimeric adiponectin by antidiabetic therapies in humans. Am J Physiol Endocrinol Metab. 2009;297(3): E767-E773.

173. Matsuoka N, Ogawa Y, Masuzaki H, et al. Decreased triglyceride-rich lipoproteins in transgenic skinny mice overexpressing leptin. Am J Physiol Endocrinol Metab. 2001;280(2):E334-E339.

174. Mazzone T, Meyer PM, Feinstein SB, et al. Effect of pioglitazone compared with glimepiride on carotid intima-media thickness in type 2 diabetes: a randomized trial. JAMA. 2006;296(21):2572-2581.

175. Lincoff AM, Wolski K, Nicholls SJ, Nissen SE. Pioglitazone and risk of cardiovascular events in patients with type 2 diabetes mellitus: a meta-analysis of randomized trials. JAMA. 2007;298(10): 1180-1188.

176. Tao L, Wang Y, Gao E, et al. Adiponectin an indispensable molecule in rosiglitazone cardioprotection following myocardial infarction. Circ Res. 2010;106(2):409-417.

177. Semenkovich CF. TZDs and diabetes: testing the waters. Nat Med. 2005;11(8):822-824.

178. Nissen SE, Wolski K. Effect of rosiglitazone on the risk of myocardial infarction and death from cardiovascular causes. $N$ Engl J Med. 2007;356(24):2457-2471.

179. Wang ZV, Scherer PE. Adiponectin, cardiovascular function, and hypertension. Hypertension. 2008;51(1):8-14.

180. Yilmaz MI, Sonmez A, Caglar K, et al. Effect of antihypertensive agents on plasma adiponectin levels in hypertensive patients with metabolic syndrome. Nephrology. 2007;12(2):147-153.

181. Koh KK, Quon MJ, Han SH, et al. Additive beneficial effects of losartan combined with simvastatin in the treatment of hypercholesterolemic, hypertensive patients. Circulation. 2004;110(24):3687-3692.

182. Kim J-A, Nunez M, Briggs DB, et al. Extracellular conversion of adiponectin hexamers into trimers. Biosci Rep. 2012;32(6):641-652.

183. Liu M, Xiang R, Wilk SA, et al. Fat-specific DsbA-L overexpression promotes adiponectin multimerization and protects mice from diet-induced obesity and insulin resistance. Diabetes. 2012;61(11):2776-2786.

184. Turer A, Scherer P. Adiponectin: mechanistic insights and clinical implications. Diabetologia. 2012;55(9):2319-2326.
Vascular Health and Risk Management

\section{Publish your work in this journal}

Vascular Health and Risk Management is an international, peerreviewed journal of therapeutics and risk management, focusing on concise rapid reporting of clinical studies on the processes involved in the maintenance of vascular health; the monitoring, prevention and treatment of vascular disease and its sequelae; and the involvement of

\section{Dovepress}

metabolic disorders, particularly diabetes. This journal is indexed on PubMed Central and MedLine. The manuscript management system is completely online and includes a very quick and fair peer-review system, which is all easy to use. Visit http://www.dovepress.com/ testimonials.php to read real quotes from published authors. 